\title{
Organizational citizenship behavior: Scale development and validation
}

\author{
Nguyen Ngoc Duy Phuong ${ }^{1 *}$, Le Nguyen Thanh Dong ${ }^{1}$ \\ ${ }^{1}$ International University, Vietnam National University Ho Chi Minh City, Vietnam \\ *Corresponding author: nndphuong@hcmiu.edu.vn
}

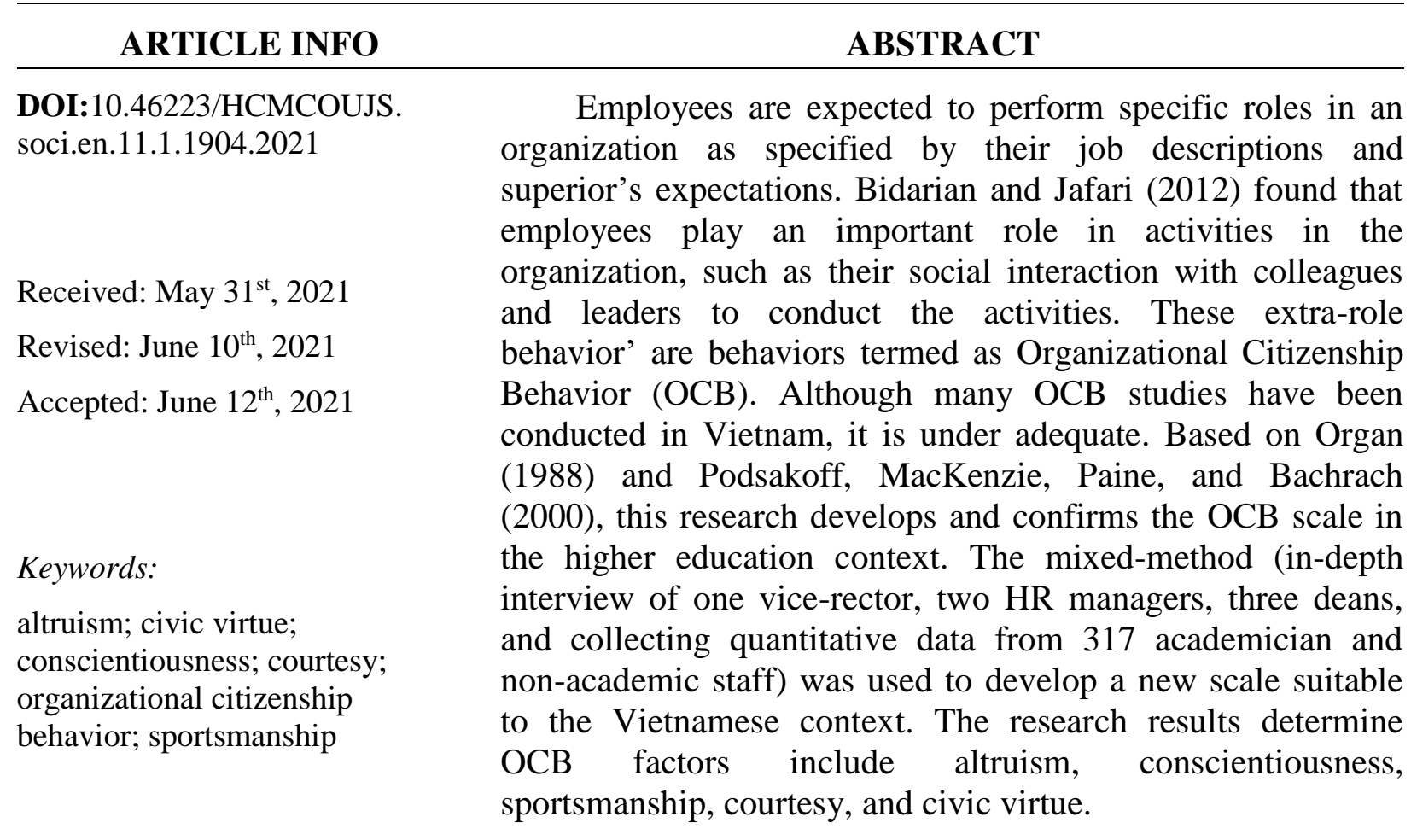

\section{Introduction}

In the management field, the efficiency of a company or improving its performance stands an extreme position in the organizational leader mindset. The simple solutions are to upgrade the technologies or enhance procedures. However, all organizations understand that human resources are the ultimate key to open the next stage. In other words, the performance of organizations is affected by the utilization of using human resources (Becker, 1962). Employees are expected to perform specific roles in an organization as specified by their job descriptions and superior's expectations. Nowadays, almost all organizations use Key Performance Index (KPI) systems as a scale to evaluate employees' performance. When an individual performs his/her tasks as described, they only meet the standard of expectations. Organizations expected their employees to perform specific tasks or exhibits particular behavior above and beyond their call of duty, such as helping their new colleagues, which are not part of their job duties. Bidarian and Jafari (2012) found that employees play an important role in activities in the organization, such as their social interaction with colleagues and leaders to conduct the activities. These 'extrarole behavior' are behaviors termed organizational citizenship behavior. Organ (1988) introduced the phenomenon of Organizational Citizenship Behavior (OCB). It is defined as "individuals' behavior that is discretionary, not directly or explicitly recognized by the formal reward system, and in the aggregate promotes the efficient and effective functioning of the organization" (p. 4). Good citizenship behavior is categorized by altruism, conscientiousness, sportsmanship, and courtesy. Organizations should consider OCB as an essential factor for 
increasing the spontaneous, innovative, and cooperative attitudes to respond to the constantly changing demands aiming to promote efficiency.

The dimensions of OCB suggested by Organ (1988) and colleagues is the inspiration for many researchers. For example, Podsakoff, MacKenzie, Moorman, and Fetter (1990) contributed to OCB by developing the fifth dimension to OCB - civic virtue. As a result, OCB can be classified into five dimensions: altruism - discretionary behaviors that have the effect of helping a specific another person with an organizationally relevant task or problem; conscientiousness discretionary behaviors on the part of the employee that goes well beyond the minimum role requirements of the organization, in the areas of attendance, obeying rules and regulations, taking breaks, and so forth; sportsmanship - the willingness of the employee to tolerate less than ideal circumstances without complaining; courtesy - discretionary behavior on the part of an individual aimed at preventing work-related problems with others from occurring; civic virtue behavior on the part of an individual that indicates that he/she responsibly participates in, is involved in or is concerned about the life of the company. To conduct OCB researches, researchers generally measured the dimensions of OCB suggested by Organ (1988) by using scales such as those developed by Podsakoff et al. (2000). Therefore, this study, the suggestion of Podsakoff et al. (2000), is used as the foundation to build and determine OCB scales.

\section{Literature review}

The term Organizational Citizenship Behavior (OCB) has been used to describe work behaviors that the formal reward system could not recognize but promotes the effective functioning of the organization (Organ, 1988). Many researchers are interested in the belief that job satisfaction, organizational commitment strength influence organizational effectiveness through behaviors that are not mentioned in the job description but managers want. Since the awareness of OCB by Organ (1988), attention to behaviors that suitable for the definition of OCB has increased dramatically (Podsakoff et al., 2000).

Organ, Podsakoff, and MacKenzie (2005) argued that satisfied employees have higher OCB because they want to reciprocate to the organization that already treats them well. Wagner and Hollenbeck (2010) strengthen this notion. Numerous pieces of literature regarding the relationship between job satisfaction and OCB are easily obtained. When the satisfaction was high, then OCB increased. Other scholars such as Foote and Li-Ping Tang (2008); Intaraprasong, Dityen, Krugkrunjit, and Subhadrabandhu (2012); Mohammad, Quoquab, and Alias (2011); and Talachi, Gorji, and Boerhannoeddin (2014) also found a positive and significant relationship between job satisfaction and OCB. That is, the individual who satisfied with the job displayed high OCB. In addition, Prasetio, Yuniarsih, and Ahman (2017) have found that job satisfaction has a positive and significant effect on OCB with a correlation of 0.334 .

O'Reilly and Chatman (1986) have found that OCB dimensions such as identification and internalization were positively related to OCB-type behaviors. Later, Schappe (1998) considered job satisfaction, procedural justice, and OC to investigate their influence on OCB. The organizational commitment had the only significant relationship to OCB. Rana, Iftikhar, Abbasi, and Abbas (2018) argued that committed employees were more likely to exhibit citizenship behaviors. The meta-analytic work of Organ and Ryan (1995) supported the view that commitment was related to OCB.

Motowidlo (2000) agreed that there is an overlap between OCB and performance context behaviors, such as job satisfaction and organizational commitment, but there are some critical definitional differences. Organ (1997) re-defined OCB as behavior that contributes "to the 
maintenance and enhancement of the social and psychological context that supports task performance" (p. 95). This modified definition of OCB is very similar to the suggestions by Podsakoff et al. (2000). In summary, this study conducted the five dimensions of OCB from Organ et al. (2005).

\section{Dimension of organizational citizenship behavior scale}

OCB is about discretionary behavior and contributions that are not explicitly associated with the specific job requirements. In addition, OCB has been thought of as personal and arbitrary behaviors which were not correctly defined by the formal remuneration system of the organization and generally increased the organization's performance (Bateman \& Strasser, 1984). Arbitrary means that this behavior is not among the occupational duties or role behaviors. It is not among the employees' recruitment commitment, and employees don't need to do it (Podsakoff et al., 2000).

Organ (1988) suggested a five-factor conceptualization, and it has been the foundation of much researches on OCB. These factors are:

(i) Altruism is directed towards other individuals but contributes to group efficiency by enhancing individual performance; participants help new colleagues and freely give of their time;

(ii) Conscientiousness is the clever use of time to enhance both individuals and the group; participants give more time to the organization and exert effort beyond the formal requirements;

(iii) Sportsmanship increases the amount of time spent on organizational endeavors; participants decrease whining, complaining, and carping;

(iv) Courtesy prevents problems and facilitates constructive use of time; participants give advance notices, timely reminders, and appropriate information;

(v) Civic virtue promotes the organization's interests broadly; participants voluntarily serve on committees and attend functions.

Further research on the dimensionality of OCB has concluded that future studies could condense the original five dimensions of OCB (Podsakoff, Mackenzie, \& Podsakoff, 2016a). Recent research has found support for a three-factor model of OCB: "conscientiousness" is removed, and "altruism" and "courtesy" are combined to form a single "helping" dimension (Podsakoff, MacKenzie, \& Podsakoff, 2016b), resulting in three factors: helping behavior, civic virtue, and sportsmanship. In addition, a different view on the dimensionality of OCB came from Biswas and Mazumder (2017), who divided OCB into two types: behaviors directed at specific individuals in the organization, such as courtesy and altruism; and behaviors concerned with benefiting the organization as a whole, such as conscientiousness, sportsmanship, and civic virtue. The present study employs a measure of OCB for empirical research based on the original five dimensions of OCB: altruism, conscientiousness, sportsmanship, courtesy, and voice (Organ, 2018).

The first factor was referred to as "altruism" because the statements loaded on this factor pertained to help provided to a colleague or coworker, whether that help was unsolicited or responded to a request for help. The help could take the form of aiding the colleague with a task by some means, such as coaching, working together to handle a big job or catch up with the flow of work, and offering encouragement and reassurance. 
A different factor in the analysis, which was initially referred to as "conscientiousness", seemed to have in common a more organizationally relevant focus rather than targeting a particular individual. Some examples of items loading on this dimension or factor were exemplary records of attendance and punctuality, maintaining a clean and orderly environment, and involvement - when appropriate - in off-hours organizational programs and projects that sustain and enhance the organizations" reputation in the community. Some of the items, such as attendance and punctuality, are more likely to be captured in the formal information system of the firm; others, if not recorded, are more apt to catch the supervisor's attention and informational expressions of gratitude.

Another dimension that could be discerned in factor analyses of the early studies seemed to have several common items describing what members do not exhibit. For example: don't rail against real or imagined slights; don't fuss about the temporary loss of privileges and conveniences; don't overload the systems with grievances, formal or otherwise; don't foul the atmosphere with negative comments about coworkers. The motion of "sportsmanship" - the idea of "rolling with the punches", accepting the fact that "in each life, some rain must fall", "accentuating the positive and eliminating the negative" - seemed to qualify as a form of OCB.

"Courtesy" came out of the analysis as a factor that had to do more with organization members' actions to prevent problems. This factor includes such gestures as giving colleagues advance notice about some development that they might need to prepare for, using ordinary resources in a fashion that leaves them problem-free for those who use them later, for example, reloading paper into the copier.

The fifth and final dimension to be added to most of the measures intended to capture OCB was "civic virtue". This factor did not emerge from some early studies because it was not proffered as a separate form of OCB distinguishable from the others and thus did not include items that might capture it. This seems surprising, given that Katz and Kahn (1966) had explicitly recognized it as a form of "spontaneous cooperation."

\section{Research methodology}

\subsection{Research methodology and sampling}

This study has used qualitative and quantitative methods to utilize the advantages of both research methods for the comprehensive valuation of the nexus of variables of the research model. The qualitative research method enables us to approach in-depth and detailed information about the views, visions, and measurements of OCB. Moreover, qualitative research with indepth expert semi-structured interviews at a face-to-face model enables authors to collect different attitudes and behaviors that potentially lead to the same action or a decision. The selected respondent types for interviews are the board of rectors, HR managers, and deans in universities. Six respondents participated in this interview, in which there were one vice-rectors, two HR managers, and three deans. The result of this phase is the final questionnaire which is suitable with research context and ready for quantitative research performing. The questionnaire was built using 7 Likert scale points, which indicates that the point ranges from 1 (strongly disagree) being ascending to 7 (strongly agree).

The participants from managers and staff of universities in Ho Chi Minh City. Survey subjects include leaders and managers - without teaching (about 06\%), leaders and managers cum lecturers (about 14\%), lecturers (about 35\%), and academic staff (about 45\%), with no age limit for respondents. The collected questionnaires were screened, and satisfied questionnaires were selected. Over 400 questionnaires were sent, but only 317 respondents are acceptable for further analysis (Hair, Hult, Ringle, \& Sarstedt, 2016). 


\subsection{Measurement}

All research concepts are based on previous studies, qualitative research results, adjusted through preliminary research, and presented in statement form. Likert scale, with seven levels from (1) strongly disagree to (7) strongly agree, is used as follows:

\section{Table 1}

Organizational citizenship behavior measurement scale

\begin{tabular}{|c|c|c|}
\hline No. & Dimensions & Resources \\
\hline $\mathbf{I}$ & Altruism (ALT): 04 items & \\
\hline 1 & Helps others who have been absent & Podsakoff and MacKenzie (1997) \\
\hline 2 & Helps others who have heavy workloads & Podsakoff and MacKenzie (1997) \\
\hline 3 & Helps orient new people even though it is not required & Podsakoff and MacKenzie (1997) \\
\hline 4 & $\begin{array}{l}\text { Willingly give your time to help others who have } \\
\text { work-related problems }\end{array}$ & Lee and Allen (2002) \\
\hline II & Conscientiousness (CON): 04 items & \\
\hline 1 & $\begin{array}{l}\text { Obeys organization's rules and regulations even when } \\
\text { no one is watching }\end{array}$ & Podsakoff and MacKenzie (1997) \\
\hline 2 & Fulfills the responsibilities described in the job description & Podsakoff and MacKenzie (1997) \\
\hline 3 & Accomplish tasks assigned by supervisors & Qualitative research \\
\hline 4 & Meet the KPIs in charged & Qualitative research \\
\hline III & Sportsmanship (SPT): 04 items & \\
\hline 1 & $\begin{array}{l}\text { Defend the organization when other employees } \\
\text { criticize it }\end{array}$ & Lee and Allen (2002) \\
\hline 2 & Show pride when representing the organization in public & Lee and Allen (2002) \\
\hline 3 & Demonstrate concern about the image of the organization & Lee and Allen (2002) \\
\hline 4 & $\begin{array}{l}\text { Offer ideas to improve the functioning of the } \\
\text { organization }\end{array}$ & Lee and Allen (2002) \\
\hline IV & Courtesy (COT): 03 items & \\
\hline 1 & Is mindful of how his/her behavior affects other people's job & Podsakoff and MacKenzie (1997) \\
\hline 2 & Tries to avoid creating problems for coworkers & Podsakoff and MacKenzie (1997) \\
\hline 3 & $\begin{array}{l}\text { Take action to protect the organization from potential } \\
\text { problems }\end{array}$ & Lee and Allen (2002) \\
\hline $\mathbf{V}$ & Civic virtue (CIV): 04 items & \\
\hline 1 & $\begin{array}{l}\text { Attends functions that are not required but help the } \\
\text { organization's image }\end{array}$ & Podsakoff and MacKenzie (1997) \\
\hline 2 & Keeps abreast of changes in the organization & Podsakoff and MacKenzie (1997) \\
\hline 3 & Share personal property with others to help their work & Lee and Allen (2002) \\
\hline \multirow[t]{2}{*}{4} & Maintain and implement organizational cultures & Qualitative research \\
\hline & Total: 19 items & \\
\hline
\end{tabular}

Source: The authors' data analysis 


\section{Data analysis}

\subsection{Cronbach's Alpha}

The Cronbach's Alpha Test is used to check scale reliability. All scales meet the reliability requirements: Cronbach's Alpha of the scales is greater than 0.7. Only one item of courtesy, if deleted, will increase the alpha from 0.74 to 0.82 . After an in-depth review, the decision to maintain all items is given.

\section{Table 2}

Cronbach's Alpha results

\begin{tabular}{|l|c|c|}
\hline \multicolumn{1}{|c|}{ Factor } & Cronbach's Alpha & No. of items \\
\hline Altruism (ALT) & $\alpha=0.957$ & 04 \\
\hline Conscientiousness (CON) & $\alpha=0.931$ & 04 \\
\hline Sportsmanship (SPT) & $\alpha=0.950$ & 04 \\
\hline Courtesy (COT) & $\alpha=0.740$ & 03 \\
\hline Civic virtue (CIV) & $\alpha=0.903$ & 04 \\
\hline
\end{tabular}

Source: Data analysis result of the research

\subsection{Exploratory Factor Analysis (EFA)}

Table 3 showed that all factor loadings are greater than 0.5, and the KMO index is 0.883 , which indicates that the scale is suitable. Furthermore, the significance in Bartlett's test has a value of 0.000 (< 0.05), a standard fit (Hair, Wolfinbarger, Money, Samouel, \& Page, 2015), proves that this scale is by the exploratory factor analysis (EFA) criteria.

\section{Table 3}

KMO and Bartlett's test

\begin{tabular}{ll|l} 
Kaiser-Meyer-Olkin Measure of Sampling Adequacy. & .883 \\
\hline Bartlett's Test of Sphericity & Approx. Chi-Square & $5,210.868$ \\
\cline { 2 - 3 } & df & 171 \\
\hline Sig. & .000 \\
\hline
\end{tabular}

Source: Data analysis result of the research

The eigenvalue of the OCB factor shows that the number of factors including Altruism (ALT), Conscientiousness (CON), Sportsmanship (SPT), Courtesy (COT), and Civic virtue (CIV). Moreover, that the Total Variance Explained index reaches $81.768 \%$ (> 50\%) meets the required standard. Finally, Factor loading shows the correlation level between observed variables and factors. 


\section{Table 4}

Total variance explained

\begin{tabular}{|c|c|c|c|c|c|c|c|c|c|}
\hline \multirow[b]{2}{*}{ Component } & \multicolumn{3}{|c|}{ Initial Eigenvalues } & \multicolumn{3}{|c|}{ Extraction Sums of Squared Loadings } & \multicolumn{3}{|c|}{ Rotation Sums of Squared Loadings } \\
\hline & Total & $\%$ of Variance & Cumulative \% & Total & $\%$ of Variance & Cumulative \% & Total & $\%$ of Variance & Cumulative $\%$ \\
\hline 1 & 7.361 & 38.741 & 38.741 & 7.361 & 38.741 & 38.741 & 3.584 & 18.864 & 18.864 \\
\hline 2 & 2.728 & 14.359 & 53.100 & 2.728 & 14.359 & 53.100 & 3.409 & 17.940 & 36.804 \\
\hline 3 & 2.122 & 11.170 & 64.270 & 2.122 & 11.170 & 64.270 & 3.383 & 17.804 & 54.608 \\
\hline 4 & 1.980 & 10.422 & 74.691 & 1.980 & 10.422 & 74.691 & 3.133 & 16.489 & 71.097 \\
\hline 5 & 1.345 & 7.077 & 81.768 & 1.345 & 7.077 & 81.768 & 2.028 & 10.671 & 81.768 \\
\hline 6 & .717 & 3.772 & 85.541 & & & & & & \\
\hline
\end{tabular}

Source: Data analysis result of the research

The Exploratory Factor Analysis showed in Table 5 indicated that 19 items of OCB had been classified into intended categories, named as altruism, sportsmanship, conscientiousness, civic virtue, and courtesy.

\section{Table 5}

Rotated Component matrix ${ }^{\mathrm{a}}$

\section{Component}

\begin{tabular}{|c|c|c|c|c|c|}
\hline & 1 & 2 & 3 & 4 & 5 \\
\hline ALT3 & .899 & & & & \\
\hline ALT2 & .891 & & & & \\
\hline ALT1 & .889 & & & & \\
\hline ALT4 & .871 & & & & \\
\hline SPT3 & & .877 & & & \\
\hline SPT2 & & .861 & & & \\
\hline SPT4 & & .850 & & & \\
\hline SPT1 & & .833 & & & \\
\hline CON2 & & & .923 & & \\
\hline CON3 & & & .896 & & \\
\hline CON4 & & & .881 & & \\
\hline CON1 & & & .868 & & \\
\hline CIV4 & & & & .870 & \\
\hline CIV1 & & & & .866 & \\
\hline CIV3 & & & & .821 & \\
\hline CVI2 & & & & .806 & \\
\hline COT2 & & & & & .878 \\
\hline COT3 & & & & & .833 \\
\hline COT1 & & & & & .698 \\
\hline
\end{tabular}

Extraction Method: Principal Component Analysis.

Rotation Method: Varimax with Kaiser Normalization.

a. Rotation converged in 05 iterations.

Source: Data analysis result of the research 


\section{Discussion \& conclusion}

The Organizational Citizenship Behavior scale is based on the definition by Organ (1988) with five dimensions and developed by the contribution of other scholars. From this definition, the study, based on Podsakoff and MacKenzie (1997), Lee and Allen (2002), and qualitative research, has developed an OCB scale.

In original, the Organ's OCB scale has 24 items. These items included five items in conscientiousness, five items in sportsmanship, four items in civic virtue, five items in courtesy, and five items in altruism. Lee and Allen (2002) classified OCB into OCBI and OCBO with 16 items. OCBI means behaviors directed to individuals, and OCBO means behaviors directed to the organization. However, these scale contents are not appropriate in Asia, particularly in the Vietnamese context. Therefore, qualitative research is mandatory to fulfill these gaps. Because of the rapid change of working environment and the technology and business context, the proposal OCB scale has been combined with the Organ's scale, Lee's scale, and qualitative research's results. As a result, the scale has 19 items divided into five factors (altruism, conscientiousness, sportsmanship, courtesy, and civic virtue) as Organ's model.

In the conscientiousness factor, qualitative research contributes to items: accomplish tasks assigned from supervisors and meet the KPIs in charge are valuable. Because of the industrial evolution 4.0, organizations are it difficult to mention all functions in job descriptions. The change of technology has created more and more "un-named tasks." Furthermore, almost every organization change their management into MBO (Management By Objective), which assigned every position in specific KPI (Key Performance Index). Therefore, the contribution of two new items is suitable for the new business context. The factor of civic virtue has been renewed with the item "maintain and implement organizational cultures" bring the term "organizational cultures" into OCB. Organizational cultures are central in governing the understanding of behavior, social events, institutions, and processes in organizations (Alvesson, 2012). Both scales from Organ and Lee have been combined for creating a new scale in other factors. This combination has the advantages of keeping the original model but add-in new items suitable to the modern context.

The purpose of this research was to point out some light on the OCB research. However, many studies of OCB, but the research of OCB in Vietnam context are under adequate. Moreover, almost OCB studies were used original scales from western scholars, which may not be fitted in the Vietnamese context. Therefore, this study could be used as the OCB scale in Vietnam for further research. The present findings also suggest that organization managers have to pay more attention to organizational citizenship behaviors; they may provide a richer understanding of employees' feelings and behaviors at work. This study, once again, showed that all five factors of OCB have a vital contribution to employees' behaviors as good citizens in an organization. Many studies have proved the relationship between OCB and organizational outcomes. Thus, increase OCB will lead to improving organizational performance. The low overall response rate and the non-probabilistic use in this study may raise concerns that our sample differed from its population on various characteristics. However, the response rate is not likely to adversely affect the validity of findings (Schalm \& Kelloway, 2001). Moreover, all respondents are from universities, which could lead to some modifications when implicating organizations beyond the higher education field. Finally, we reiterate our concern that investigates the scale in predicting organizational citizenship behaviors is a challenging and complex endeavor. Nonetheless, we believe this to be important as OCB in the Vietnamese context is emerging. We look forward to future research that attempts to contribute both in theoretical and empirical on OCB. 


\section{ACKNOWLEDGEMENTS}

This research is funded by Vietnam National University Ho Chi Minh City (VNU-HCM) under grant number C2020-28-05.

\section{References}

Alvesson, M. (2012). Understanding organizational culture. London, UK: SAGE Publications Ltd.

Bateman, T. S., \& Strasser, S. (1984). A longitudinal analysis of the antecedents of organizational commitment. Academy of Management Journal, 27(1), 95-112.

Batman, T. (1983). Job satisfaction and the soldier: The relationship between affect and employee Citizenship. Academy of Management Journal, 26(4), 587-595.

Becker, G. S. (1962). Investment in human capital: A theoretical analysis. Journal of Political Economy, 70(5), 9-49.

Bidarian, S., \& Jafari, P. (2012). The relationship between organizational justice and organizational trust. Procedia - Social and Behavioral Sciences, 47(2012), 1622-1626. doi:10.1016/j.sbspro.2012.06.905

Biswas, N., \& Mazumder, Z. (2017). Exploring organizational citizenship behavior as an outcome of job satisfaction: A critical review. IUP Journal of Organizational Behavior, 16(2), 7-16.

Foote, D. A., \& Li-Ping Tang, T. (2008). Job satisfaction and Organizational Citizenship Behavior (OCB) does team commitment make a difference in self-directed teams? Management Decision, 46(6), 933-947.

Hair, J. F., Jr Wolfinbarger, M., Money, A. H., Samouel, P., \& Page, M. J. (2015). Essentials of business research methods. London, UK: Routledge.

Hair, J. F., Jr., Hult, G. T. M., Ringle, C., \& Sarstedt, M. (2016). A primer on Partial Least Squares Structural Equation Modeling (PLS-SEM). London, UK: Sage publications.

Intaraprasong, B., Dityen, W., Krugkrunjit, P., \& Subhadrabandhu, T. (2012). Job satisfaction and organizational citizenship behavior of personnel at one university hospital in Thailand. Journal of the Medical Association of Thailand, 95(6), S102-S108.

Katz, D., \& Kahn, R. L. (1966). The social psychology of organizations. New York, NY: Wiley.

Lee, K., \& Allen, N. J. (2002). Organizational citizenship behavior and workplace deviance: The role of affect and cognitions. Journal of Applied Psychology, 87(1), 131-142.

Mohammad, J., Quoquab, F., \& Alias, M. (2011). Job satisfaction and organisational citizenship behaviour: An empirical study at higher learning institutions. Asian Academy of Management Journal, 16(2), 149-165.

Motowidlo, S. J. (2000). Some basic issues related to contextual performance and organizational citizenship behavior in human resource management. Human Resource Management Review, 10(1), 115-126.

O'Reilly, C. A., \& Chatman, J. (1986). Organizational commitment and psychological attachment: The effects of compliance, identification, and internalization on prosocial behavior. Journal of Applied Psychology, 71(3), 492-499.

Organ, D. W. (1988). Organizational citizenship behavior: The good soldier syndrome. Lexington, MA: Books/DC Heath and Com.

Organ, D. W. (1997). Organizational citizenship behavior: It's construct clean-up time. Human Performance, $10(2), 85-97$. 
Organ, D. W. (2018). The roots of organizational citizenship. In P. M. Podsakoff, S. B. Mackenzie \& N. P. Podsakoff (Eds.), The Oxford handbook of organizational citizenship behavior (pp.169-184). Oxford, UK: Oxford University Press.

Organ, D. W., \& Ryan, K. (1995). A meta-analytic review of attitudinal and dispositional predictors of organizational citizenship behavior. Personnel Psychology, 48(4), 775-802.

Organ, D. W., Podsakoff, P. M., \& MacKenzie, S. B. (2005). Organizational citizenship behavior: Its nature, antecedents, and consequences. London, UK: Sage Publications.

Podsakoff, P. M., \& MacKenzie, S. B. (1997). Impact of organizational citizenship behavior on organizational performance: A review and suggestion for future research. Human Performance, 10(2), 133-151.

Podsakoff, P. M., Mackenzie, S. B., \& Podsakoff, N. P. (2016a). Organizational citizenship behavior: Introduction and overview of the handbook. In P. M. Podsakoff, S. B. Mackenzie \& N. P. Podsakoff (Eds.), The Oxford handbook of organizational citizenship behavior (pp. 1-5). New York, NY: Oxford University Press.

Podsakoff, P. M., MacKenzie, S. B., \& Podsakoff, N. P. (2016b). Recommendations for creating better concept definitions in the organizational, behavioral, and social sciences. Organizational Research Methods, 19(2), 159-203.

Podsakoff, P. M., MacKenzie, S. B., Moorman, R. H., \& Fetter, R. (1990). Transformational leader behaviors and their effects on followers' trust in leader, satisfaction, and organizational citizenship behaviors. The Leadership Quarterly, 1(2), 107-142.

Podsakoff, P. M., MacKenzie, S. B., Paine, J. B., \& Bachrach, D. G. (2000). Organizational citizenship behaviors: A critical review of the theoretical and empirical literature and suggestions for future research. Journal of Management, 26(3), 513-563.

Prasetio, A. P., Yuniarsih, T., \& Ahman, E. (2017). Job satisfaction, organizational commitment, and organizational citizenship behaviour in state-owned banking. Universal Journal of Management, 5(1), 32-38.

Rana, M. S., Iftikhar, U., Abbasi, S. G., \& Abbas, M. (2018). The role of organizational justice to develop organizational citizenship behavior: Moderating effect of Islamic work ethics. Revista Amazonia Investiga, 7(16), 46-60.

Schalm, R. L., \& Kelloway, E. K. (2001). The relationship between response rate and effect size in occupational health psychology research. Journal of Occupational Health Psychology, 6(2), 160-163.

Schappe, S. P. (1998). The influence of job satisfaction, organizational commitment, and fairness perceptions on organizational citizenship behavior. The Journal of Psychology, 132(3), 277-290.

Talachi, R. K., Gorji, M. B., \& Boerhannoeddin, A. B. (2014). An investigation of the role of job satisfaction in employees' organizational citizenship behavior. Collegium Antropologicum, $38(2), 429-436$.

Wagner, J., \& Hollenbeck, J. (2010). Organizational behavior: Securing competitive advantage. New York, NY: Routledge.

Creative Commons Attribution-NonCommercial 4.0 International License. 